\title{
Ethics of Human Enhancement: An Executive Summary
}

\author{
Fritz Allhoff • Patrick Lin • Jesse Steinberg \\ F. Allhoff \\ Department of Philosophy, Western Michigan University, Kalamazoo, MI 49008, USA \\ e-mail: fritz.allhoff@wmich.edu \\ P. Lin \\ Department of Philosophy, California Polytechnic State University, San Luis Obispo, \\ CA 93407, USA \\ e-mail: palin@calpoly.edu \\ J. Steinberg \\ Division of Behavioral and Social Sciences, University of Pittsburgh at Bradford, Bradford, \\ PA 16701, USA \\ e-mail: steinbe@pitt.edu
}

With multi-year funding from the U.S. National Science Foundation (NSF), a team of researchers has just released a comprehensive report detailing ethical issues arising from human enhancement (Allhoff et al. 2009). While we direct the interested reader to that (much longer) report, we also thank the editors of this journal for the invitation to provide an executive summary thereof. This summary highlights key results from each section of that report and does so in a self-standing way; in other words, this summary presupposes no familiarity with the report and offers the opportunity to gain quick familiarity with its most central findings.

\section{What Is Enhancement?}

"Man is the only creature that refuses to be what he is" (Camus 1951, p. 11). Homo sapiens has been such a prolific species, simply because we are relentlessly proficient at adapting to our environment. At the most basic level, we have won control over fire and tools to forge a new world around us: we build shelter and weave clothes to repel the brutal elements, and we raise animals and crops for 
predictability in our meals. With intellect and resourcefulness, we are better able to survive this world.

However, it is not just the world around us that we desire to change. Since the beginning of history, we also have wanted to become more than human, to become Homo superior. From the godlike command of Gilgamesh, to the lofty ambitions of Icarus, to the preternatural strength of Beowulf, to the mythical skills of Shaolin monks, and to various shamans and shapeshifters throughout the world's cultural history, we have dreamt - and still dream-of transforming ourselves to overcome our all-too-human frailties and limitations.

In practice, this means that we improve our minds through education, disciplined thinking, and meditation. We improve our bodies with a sound diet and physical exercise, and we train with weapons and techniques to defend ourselves from those who would conspire to kill. But today, something seems to be different. With ongoing work to unravel the mysteries of our minds and bodies, coupled with the art and science of emerging technologies, we are near the beginning of the Human Enhancement Revolution.

Now we are no longer limited to "natural" methods to enhance ourselves or to merely wield tools such as a hammer or binoculars or a calculator. We are beginning to incorporate technology within our very bodies, which may hold moral significance that we need to consider. These technologies promise great benefits for humanity - such as increased productivity and creativity, longer lives, greater serenity, stronger bodies and minds, and more-though there is a question of whether these things translate into happier lives, which many see as the point of it all (President's Council on Bioethics 2003; Persaud 2006).

As examples of emerging technologies in the last year or so, several imaginative inventions in particular are closing the gap even more between science fiction and the real world. Scientists have conceptualized an electronic-packed contact lens that may provide the wearer with telescopic and night vision or act as an omnipresent digital monitor to receive and relay information (Parviz et al. 2008). Another innovation is a touch display designed to be implanted just under the skin that would activate special tattoo ink on one's arm to form images, such as telephone-number keys to punch or even a video to watch (Mielke 2008). Together with ever-shrinking computing devices, we appear to be moving closer to cybernetic organisms (or "cyborgs"); that is, where machines are integrated within our bodies or at least into our clothing in the nearer-term. Forget about Pocket PCs, mobile phones, GPS devices, and other portable gadgets; we might soon be able to communicate and access those capabilities without having to carry any external device, thus raising our productivity, efficiency, response time, and other desirable measures-in short, enabling us to even better survive our world.

Technology is clearly a game-changing field. The invention of such things as the printing press, gunpowder, automobiles, computers, vaccines, and so on, has profoundly changed the world, for the better we hope. But at the same time, they have also led to unforeseen consequences, or perhaps consequences that might have been foreseen and addressed had we bothered to investigate them. Least of all, they have disrupted the status quo, which is not necessarily a terrible thing in and of itself; but unnecessary and dramatic disruptions, such as mass displacements of 
workers or industries, have real human costs. As we will discuss, this may well be the case with human enhancement technologies, enabled by advances in nanotechnology, micro-electro-mechanical systems (MEMS), genetic engineering, robotics, cognitive science, information technology, pharmacology, and other fields (Roco and Bainbridge 2003). ${ }^{1}$

The NSF report is an examination of many social and ethical issues surrounding human enhancement technologies. For example, concerning the issue of whether such technologies ought to be regulated or otherwise restricted, one position is that (more than minimal) regulation would hinder personal freedom or autonomy, infringing on some natural or political right to improve our own bodies, minds, and lives as we see fit (Naam 2005; Bailey 2005; Harris 2007; Allhoff et al. 2010). Others, however, advocate strong regulation - and even a research moratorium-to protect against unintended effects on society, such as the presumably-undesirable creation of a new class of enhanced persons who could outwit, outplay, and outlast "normal" or unenhanced persons for jobs, in schools, at sporting contests, and so on (Fukuyama 2002, 2006; Friends of the Earth 2006). Still others seek a sensible middle path between stringent regulation and individual liberty (Hughes 2004; Greely 2005).

No matter where one is aligned on this issue, the human enhancement debate is a deeply passionate and personal one, striking at the heart of what it means to be human. Some see it as a way to fulfill or even transcend our potential; others see it as a darker path towards becoming Frankenstein's monster. To help untangle this debate, the NSF report is comprised of a list of questions and answers, starting with background issues and moving to specific concerns, including: freedom \& autonomy, health \& safety, fairness \& equity, societal disruption, and human dignity. The report does not represent an exhaustive discussion of these issues; indeed, many of these questions would require a book-length treatise for any satisfying answer. Rather, the report is intended as a broad survey of the human enhancement landscape and its main contours, not its more intricate rabbit holes and subtler terrain, as other and future investigations will surely explore.

\section{Definitions and Distinctions}

Strictly speaking, "human enhancement" includes any activity by which we improve our bodies, minds, or abilities - things we do to enhance our well-being (Lin and Allhoff 2008). But it is tempting to think that "human enhancement" is about boosting our capabilities beyond the species-typical level or statisticallynormal range of functioning for an individual (Daniels 2000). Consider the following illustrative examples. As it concerns the mind, taking Ritalin to treat attention-deficit hyperactivity disorder (ADHD) is aimed at correcting the deficit; but taken by otherwise-normal students to enable them to focus better in studying

\footnotetext{
${ }^{1}$ For an overview of ethical and social issues of nanotechnology beyond its role in human enhancement, see Allhoff and Lin 2006; Lin and Allhoff 2007; Allhoff et al. 2007; Allhoff and Lin 2008; and Allhoff et al. 2010 .
} 
for exams is a form of human enhancement. And where reading a book may indeed make you more knowledgeable, it does not make you so much smarter than most everyone else or push your intellect past natural limits; on the other hand, a computer chip implanted into your brain that gives you direct access to Google or spreadsheets would provide mental capabilities beyond the species-typical level.

Since, strictly speaking, human enhancements seem to include such activities as reading a book and eating vegetables it might appear that these "natural" enhancements are ethically unproblematic. It would be tempting to draw a line here in the human enhancement debate such that "artificial" or "unnatural" enhancements require moral evaluation. However, this approach is problematic. First, there appears to be vagueness as to what should count as "natural." In addition, the distinction between natural and artificial might objectionably rest on dubious theological or teleological premises (e.g., that we have God-given goals or limits in life such that living to 300 would be profanely unnatural or in violation of God's will).

One might be tempted by the thought that the internal-external distinction is morally significant insofar as one might think that human enhancements that are internal are morally questionable, whereas those that are external are not. In other words, the use of tools is perfectly moral, but incorporating tools as part of our bodies is morally questionable. However, it could also be maintained that a neural implant that gives access to Google and the rest of the online world does not seem to be different in kind to using a laptop computer or Pocket PC to access the same. So why should it matter that we are imbedding computing power into our heads rather than carrying the same capabilities with us by way of external devices?

\section{Context and the Moral Status of Enhancement}

What counts as an enhancement and whether it is morally relevant seems to be context-dependent. For example, we can imagine a society in which strict equality is the over-arching value, trumping individual rights to life, liberty, knowledge, and so on; thus immunizing a person from a serious disease might be prohibited in such a world so to not upset egalitarian values or disrupt social institutions that strongly rely on a certain range of life expectancy, e.g., a social security system. Another example: freely burning fossil fuels was less morally significant in 1910 than it is in 2010, given the current state of global warming, pollution, and their causes and effects. Therefore, context matters, and so it seems premature to say that all enhancements are morally worrisome, irrespective of context; but it is also premature to declare all of them to be unproblematic, especially at a start of debate exactly about those questions.

In this regard, we might also make an argument that strict equality is not morally required in the first place, given the natural and manageable range of variations in our species; but if some future vaccine takes us well beyond this "normal" range, e.g., super-longevity or super-strength, our social systems (including law and public policy) are not equipped to account for those extra abilities, thereby raising latent issues of equity, fairness, access, etc. Similarly, we can imagine a world in which 
cognitive enhancements no longer hold much controversy as they do today, after social structures in the future have adapted to account for them-just like, e.g., steroid use in sports might no longer be an ethical issue (perhaps only a health issue) if we create separate competitions for the enhanced as well as unenhanced. Again, context seems to matter.

\section{Freedom and Autonomy}

There is perhaps no greater value, at least in democracies, than the cherished concept of freedom, loosely defined here as the absence of constraints. But because freedom is central to the issue of human enhancement, it adds much fuel to the impassioned debate. Pro-enhancement advocates have argued against regulating enhancements on the grounds that it would infringe on our fundamental ability to choose how we want to live our own lives (Naam 2005; Bailey 2005; Harris 2007). Or, in other words, if enhancing our bodies does not hurt anyone (other than possibly ourselves), then why should we be prevented from doing so? This is a common objection-arguing especially against governmental intervention - to any number of proposals that involve regulation, from hiring practices to home improvements to school clothing, and so on.

Though freedom may be viewed in democracies as a "sacred cow" that ought not be corralled, the reality is that we do not have complete freedom in the areas of life that we think we do anyway. As examples, freedom of the press and freedom of speech do not protect the individual from charges of libel, slander, or inciting panic by yelling "Fire!" in a crowded theater; our privacy expectations quietly give way to security measures, such as searches on our property and persons at airports or eavesdropping on our communications; and even ancestral homes built by the hands of one's forefathers could be unilaterally seized (and demolished) by the state under eminent domain laws. This is to say that whatever rights we have also imply responsibilities and exist within some particular political system. Therefore, it is not unreasonable to expect or define certain limits for those rights, especially where they conflict with other rights and obligations.

Maximal freedom is a hallmark of a laissez-faire or minimal state, but a democratic society is not compelled to endorse such a stance, as some political philosophers have suggested (e.g., Nozick 1974). Nor would reasonable people necessarily want unrestricted freedom anyway, e.g., no restrictions or background checks for gun ownership. Even the most liberal democracy today understands the value of regulations as a way to enhance our freedom. For instance, our economic system is not truly a "free market": though we may advocate freedom in general, regulations exist not only to protect our rights, but also to create an orderly process that greases the economic wheel, accelerating both innovations and transactions. As a simpler example, by imposing laws on traffic, we can actually increase our freedom: by driving forward on only one side of the road, we can be (more) assured that we will not be a victim of a head-on collision, which makes driving faster a more sensible proposition. 
There is another sense, related to free will, in which cognitive enhancements may be infringing: if an enhancement, such as a mood-altering drug or neural implant, interferes with or alters our deliberative process, then it is an open question whether or not we are truly acting freely while under the influence of the enhancement. For instance, a "citizen chip" embedded in the brain might cause us to be unswervingly patriotic and hold different values than we would otherwise. Further, external pressure from peers, employers, competitors, national security, and others to accept a particular enhancement also may unduly influence one's decision making (Guston et al. 2007). Such considerations have some obvious moral implications.

\section{Fairness and Equity}

It is certainly understandable that one might desire or even feel pressure to enhance one's self or children, but it is important to note the following: advantages gained by enhanced persons also imply a relative disadvantage for the unenhanced, whether in sports, employment opportunities, academic performance, or any other area. That is to say, fairness is another value to consider in the debate. A related worry is that the wealthy would be the first adopters of human enhancement technologies, given that they can best afford such innovations (like LASIK eye surgery), thus creating an even wider gap between the haves and the have-nots (McKibben 2004).

In considering the issue of fairness, we need to be careful not to conflate it with equity. Under most economic theories, fairness does not require that we need to close the gap entirely between economic classes, even when justice is defined as fairness (Rawls 1971; for an application of Rawls to enhancement, see Allhoff 2005). Indeed, there are good reasons to think that we want some gap to exist, for example, to provide incentives for innovations, in order to move up the economic ladder, and to allow flexibility in a workforce to fill vacancies and perform a wide range of tasks. At least some competition seems to be desirable, especially when resources to be allocated are limited.

Thus, inequality itself is not so much the point, though any poverty or decline in welfare related to increased inequality may be a serious concern. We do not want people to stop striving to improve their own lives, even if the situation for others is not improved at the same time or ever. And natural advantages and inequities already exist without moral issues anyway; Hobbes recognized that these organic differences did not give any individual or group of individuals so much net advantage that they would be invulnerable to the "solitary, poor, nasty, brutish, and short" conditions that mark human life (Hobbes 1651, p. I.xiii.9).

If human enhancement technologies develop as predicted, they can afford us a tremendous advantage in life; e.g., over others in a competition for resources, so much so that it overstretches the natural range of equality to the point where inequality becomes a more salient issue. This is where the gap between enhanced and unenhanced persons may be too wide to bridge, making the latter into dinosaurs in a hypercompetitive world. If we assume that the benefits of being an enhanced person must be largely paid from the welfare of others, e.g., a job-gain by one person is a job-loss by another. Since the others are now at a relative disadvantage, 
this may further impoverish the unenhanced, which may limit their access to such things as healthcare, legal representation, political influence, and so on.

\section{Social Disruptions}

Fairness and equality are not just theoretical values, but they have practical effects. Gross inequality itself, whether fair or not, can motivate the worse-off masses to revolt against a state or system. But societal disruption need not be so extreme to be taken seriously. Entire institutions today-as well as the lack thereof-are based on a specific range of abilities and rough equality of natural assets. Sports, for instance, would change dramatically, if enhanced persons are permitted to compete to the clear disadvantage of unenhanced athletes, smashing their previous records. (This is not to say that sports should ban enhanced competitors, only that doing so would have a real, significant affect on careers and expend valuable resources to adjust sporting programs and contests.)

Other institutions and systems include economic, privacy, communications, pensions, security, and many other sectors of society. For instance, if life-extension technologies can increase our average lifespan by 20 years-let alone the $100+$ years predicted by some futurists (Kurzweil 2005; de Grey 2007), and assuming that the extra 20 years will be a good life, not one bogged down with illness and diminishing productivity that afflict many elderly today-then we would need to radically adjust retirement programs: do we move the retirement age to 85 , which has negative consequences for job-seekers such as new tenure-track academic faculty, or increase contributions to pension plans, which puts pressure on household budgets and employers? Or both? Also, assuming birth rates do not decline (which causes problems of its own), longer lives will mean more pressure on resources such as energy and food.

Some scenarios that may cause social disruption include: a job candidate with a neural implant that enables better data retention and faster information processing would consistently beat out unenhanced candidates; a person with super-human hearing or sight could circumvent existing privacy protections and expectations by easily and undetectably eavesdropping or spying on others; more students (and professors) using Ritalin may grab admission or tenure at all the best universities, and so on.

\section{Human Dignity and the Good Life}

The fiercest resistance to human enhancement technologies is perhaps a concern about their effect on "human dignity" and what it means to be human (President's Council on Bioethics 2003; Sandel 2007). For instance, does the desire for enhancement show ingratitude for what we have and (further) enable an attitude of unquenchable dissatisfaction with one's life? Some researchers suggest that discontent is hardwired into the genetic makeup of humans (Hill 2006; Woodall 2007), which is why we constantly innovate, strive to achieve and gain more, etc. 
However, even if this is true, it does not seem to be so much an argument to promote human enhancement technologies, but more a worry that those technologies are not the panacea or Holy Grail of happiness we might believe them to be. That is, we will still be dissatisfied with ourselves no matter how much we enhance ourselves (unless, of course, we somehow eradicate that part of our DNA that causes discontent).

Would human enhancement technologies hinder moral development? Many believe that "soul-making" is impossible without struggle (Hick 1966), and achievements ring hollow without sacrifice or effort (President's Council on Bioethics 2003); so if technology makes life and competitions easier, then we may lose opportunities to feed and grow our moral character. On the other hand, compare our lives today with pre-Internet days: increased connectivity to friends, work, information, etc. is often a double-edged proposition that also increases stress and decreases free time. This, then, raises the related concern of whether enhancement technologies will actually make our lives happier. (If the research mentioned above about discontent in our genes is accurate, then we might have a psychobiological reason to think not.)

Is the frailty of the human condition necessary to best appreciate life? There is something romantic about the notion of being mortal and fallible. But with existing pharmacology, we could eliminate the emotion of sadness today, and work is continuing on drugs that repress memories; but it is not clear that sadness (at least in the normal range, as opposed to clinical depression) is a "pathology" we should want to eliminate, rather than a human experience that we should preserve (President's Council on Bioethics 2003). Other critics have suggested that life could be too long, leading to boredom after one's life-goals are achieved (e.g., Williams 1973).

Finally, there might be concern that we are playing God with world-changing technologies, which is presumably bad (Peters 2007). But what exactly counts as "playing God", and why is that morally wrong; i.e., where exactly is the proscription in religious scripture? If we define the concept as manipulating nature, then we all have been guilty of that since the first man picked up a stick. Making life-and-death decisions is a plausible candidate as a definition, but then physicians as well as soldiers (even in holy wars?) could be accused of this charge.

\section{Rights and Obligations}

Rights can be divided into two broad classes: a class of human rights, sometimes called "natural rights", and a class of more conventional rights based on the specific customs, roles, and laws of a society. Examples of the former are famously listed in the American Declaration of Independence: "We hold these truths to be self-evident, that all men are created equal, that they are endowed by their Creator with certain unalienable Rights, that among these are Life, Liberty and the pursuit of Happiness." The right to enhancement is not specifically included in this list or in other familiar lists of human rights. But it could be argued that a right of enhancement is a right derived from some or all of the human rights like those listed in the Declaration of Independence. Humans should be able to exercise their right to enhancements to the extent that it promotes their life, liberty, or the pursuit of happiness. 
However, this at most would make a right to enhancement a prima facie right because human rights themselves, though fundamental, can conflict and are susceptible to modification and qualification. One's right to liberty, for example, does not automatically permit infringement on the rights of others. Rights frequently trump one another in our considerations about which action is correct. But rights can also be trumped by extremely harmful consequences. Therefore, even if the right to enhancement is regarded as a derived human right, its application in a particular situation could be challenged on the grounds that it infringes on the rights of others or that its exercise would lead to extreme harm.

The right to enhancement can also be regarded as conventional. "Conventional" does not mean "arbitrary" but "established by general agreement or practice." We can make laws, for example, that allow some enhancements and laws that prohibit others. How justified such conventional rights or prohibitions are depends upon how good the reasons are for them. We might easily justify the use of nanodevices that patrol our bodies for cancerous outbreaks. We would prohibit the use of nanodevices that would give humans a burst of intelligence followed by likely seizures and strokes.

\section{Policy and Law}

Given the preceding discussion, it should be clear that human enhancement is more than just about the individual's freedom or autonomy, but there are plausibly negative consequences to others and society that need to be considered. Or at least an argument needs to be made that freedom/autonomy trumps all other values, but such a position seems unacceptably dogmatic. These issues point to the policy dilemma of whether we should regulate or restrict on human enhancement technologies, so as to prevent or mitigate some of the negative impacts. Three answers suggest themselves: (1) no restrictions, (2) some restrictions, or (3) a moratorium or full ban.

A moratorium seems unrealistic to the extent that a worldwide one would be needed to truly stem the use of human enhancement technologies, and that no worldwide moratorium on anything has yet to work, including on (alleged) attempts to clone a human being. A local moratorium would send patients to "back-alley" enhancement clinics or to more liberal regions of the world, as is the case with "cosmetic-surgery vacations" in which those medical procedures are less expensive in other nations. Further, a ban on enhancement research seems much too premature - an overreaction to perceived, future risks - as well as a real threat to therapy-related research today.

On the other side of the spectrum, the idea of having no restrictions on human enhancement technologies seems to be reckless or at least unjustifiably optimistic, given that there are plausible risks. As pointed out earlier, complete freedom or autonomy may be a recipe for disaster and chaos in any case; we do not want to grant the right to yell "Fire!" in a crowded venue or the right for dangerous felons to own firearms. 
So what about finding middle ground with some non-Draconian regulations? Critics have argued that any regulation would be imperfect and likely ineffectual, much like laws against contraband or prostitution (Naam 2005); but it is not clear that eliminating these laws would improve the situation, all things considered. Also, as a society, we still believe we ought to at least try to solve social ills, even if we cannot ultimately fix the entire problem, e.g., we cannot stop any given crime from ever occurring, yet we still have laws against such acts. And even if there are practical reasons to not pursue regulations, would that send the wrong message; e.g., to children, that we support enhancement without reservations?

The issue of regulation will surely not be settled here, nor do we intend it to be. Yet it is important to keep in mind that the human enhancement debate is not just a theoretical discussion about ethics, but has bearing on the real world with policy decisions that may affect not just the would-be enhanced, but also researchers, manufacturers, social institutions, as well as our ideals of freedom and human dignity (Lin 2007).

\section{Conclusion}

This has been a short review of a number of major questions in the ethics debate on human enhancement. An impressive array of technologies is driving the urgency of this debate, from familiar drugs (e.g., steroids, modafinil, Ritalin) to fantastic visions of a cybernetic future. No one knows which visions-utopian, dystopian, or pedestrian-ultimately will be realized. But insofar as there are good reasons to think that many of these visions are plausible, it seems prudent to at least begin a conversation about the many ethical, legal, social, and political issues associated with human enhancement, especially since ethics seems to historically lag (far) behind technology and other quickly-evolving events. By planning ahead, we can be better prepared to enact legislation or regulation as deemed fit.

The NSF report represents a disinterested, sensible middle path in presenting the various sides of each issue, given the early stage of this debate, though clearly there are passionate and opposing forces engaged in this international struggle for clarity and policy. An increasing flow of thoughtful literature exists (e.g., Savulescu and Bostrom 2009), and we expect the arguments to continue for many more yearsproving the prediction that human enhancement ethics will be one of the most important debates in science and society is this brave new century.

Acknowledgement The authors of the report gratefully acknowledge the support of the NSF under awards \# 0620694 and 0621021.

\section{References}

Allhoff, F. (2005). Germ-line genetic enhancement and Rawlsian primary goods. Kennedy Institute of Ethics Journal, 15.1, 39-56.

Allhoff, F., \& Lin, P. (2006). What's so special about nanotechnology and nanoethics? International Journal of Applied Philosophy, 20.2, 179-190. 
Allhoff, F., \& Lin, P. (2008). Nanotechnology \& society: Current and emerging ethical issues. Dordrecht: Springer.

Allhoff, F., Lin, P., Moor, J., \& Weckert, J. (Eds.). (2007). Nanoethics: The ethical and social implications of nanotechnology. Hoboken, NJ: John Wiley \& Sons.

Allhoff, F., Lin, P., Moor, J., \& Weckert, J. (2009). Ethics of human enhancement: 25 questions and answers. http://www.humanenhance.com/NSF_report.pdf. Accessed 27 Nov 2009.

Allhoff, F., Lin, P., \& Moore, D. (2010). What is nanotechnology and why does it matter? From science to ethics. Hoboken, NJ: Wiley-Blackwell Publishing.

Bailey, R. (2005). Liberation biology: The scientific and moral case for the biotech revolution. Amherst, NY: Prometheus Books.

Camus, A. (1951). The Rebel: An essay on man in revolt (Vintage International edition, 1982). New York: Vintage International.

Daniels, N. (2000). Normal functioning and the treatment-enhancement distinction. Cambridge Quarterly of Healthcare Ethics, 9, 309-322.

de Grey, A. (2007). Ending aging: The rejuvenation breakthroughs that could reverse human aging in our lifetime. New York: St. Martin's Press.

Friends of the Earth. (2006). The disruptive social impacts of nanotechnology: Issue summary. http://nano.foe.org.au/node/151. Accessed 1 Aug 2009.

Fukuyama, F. (2002). Our posthuman future: Consequences of the biotechnology revolution. New York: Picador.

Fukuyama, F. (2006). Beyond bioethics: A proposal for modernizing the regulation of human biotechnologies. Washington DC: School of Advanced International Studies, Johns Hopkins University.

Greely, H. (2005). Regulating human biological enhancements: Questionable justifications and international complications. The Mind, the Body, and the Law: University of Technology, Sydney, Law Review, 7, 87-110. Santa Clara Journal of International Law, 4, 87-110 (2006) (joint issue).

Guston, D., Parsi, J., \& Tosi, J. (2007). Anticipating the ethical and political challenges of human nanotechnologies. In F. Allhoff, P. Lin, J. Moor, \& J. Weckert (Eds.), Nanoethics: The ethical and social implications of nanotechnology. Hoboken, NJ: John Wiley \& Sons.

Harris, J. (2007). Enhancing evolution: The ethical case for making ethical people. Princeton: Princeton University Press.

Hick, J. (1966). Evil and the god of love. New York: Harper and Row Publishers.

Hill, S. E. (2006). Dissatisfied by design: The evolution of discontent. Dissertation. University of Texas, Austin.

Hobbes, T. (1651). Leviathan (Penguin Classics edition, 1982). New York: Penguin Group.

Hughes, J. (2004). Citizen cyborg: Why democratic societies must respond to the redesigned human of the future. Cambridge, MA: Westview Press.

Kurzweil, R. (2005). The singularity is near: When humans transcend biology. New York: Viking Penguin.

Lin, P. (2007). Nanotechnology bound: Evaluating the case for more regulation. NanoEthics, 2, 105-122.

Lin, P., \& Allhoff, F. (2007). Nanoscience and nanoethics: Defining the disciplines. In F. Allhoff, P. Lin, J. Moor, \& J. Weckert (Eds.), Nanoethics: The ethical and social implications of nanotechnology (pp. 3-16). Hoboken, NJ: John Wiley \& Sons.

Lin, P., \& Allhoff, F. (2008). Untangling the debate: The ethics of human enhancement. NanoEthics, 2 , 251-264.

McKibben, B. (2004). Enough: Staying human in an engineered age. New York: Henry Holt \& Co.

Mielke, J. (2008). Digital tattoo interface entry at greener gadgets design competition 2008, New York, NY, February 2008. http://www.core77.com/competitions/GreenerGadgets/projects/4673/. Accessed 1 Aug 2009.

Naam, R. (2005). More than human. New York: Broadway Books.

Nozick, R. (1974). Anarchy, state, and Utopia. New York: Basic Books.

Parviz, B.A., et al. (2008). Contact lens with integrated inorganic semiconductor devices. Presentation at 21st IEEE International Conference on Micro Electro Mechanical Systems, Tuscon, AZ, 13-17 January 2008.

Persaud, R. (2006). Does smarter mean happier? In J. Wilsdon \& P. Miller (Eds.), Better humans? The politics of human enhancement and life extension. London: Demos. 
Peters, T. (2007). Are we playing god with nanoenhancement? In F. Allhoff, P. Lin, J. Moor, \& J. Weckert (Eds.), Nanoethics: The ethical and social implications of nanotechnology. Hoboken, NJ: John Wiley \& Sons.

President's Council on Bioethics. (2003). Beyond therapy: Biotechnology and the pursuit of happiness. Washington, DC: Government Printing Office.

Rawls, J. (1971). A theory of justice. Cambridge, MA: Belknap Press.

Roco, M., \& Bainbridge, W. S. (2003). Converging technologies for improving human performance: Nanotechnology, biotechnology, information technology and cognitive science. Dordrecht: Kluwer Academic Publishers.

Sandel, M. (2007). The case against perfection: Ethics in the age of genetic engineering. Cambridge, MA: Belknap Press.

Savulescu, J., \& Bostrom, N. (2009). Human enhancement. New York: Oxford University Press.

Williams, B. (1973). Problems of the self. Cambridge, UK: Cambridge University Press.

Woodall, J. (2007). Programmed dissatisfaction: Does one gene drive all progress in science and the arts? The Scientist, 21(6), 63. 